\title{
Safety Outcomes and Near-Adult Height Gain of Growth Hormone-Treated Children with SHOX Deficiency: Data from an Observational Study and a Clinical Trial
}

\author{
Imane Benabbad ${ }^{\mathrm{a}} \quad$ Myriam Rosilio $^{\mathrm{a}}$ Christopher J. Child ${ }^{\mathrm{b}} \quad$ Jean-Claude Carel $^{\mathrm{c}}$ \\ Judith L. Ross ${ }^{d, e}$ Cheri L. Deal ${ }^{f}$ Stenvert L.S. Drop ${ }^{g} \quad$ Alan G. Zimmermann $^{\text {h }}$ \\ Nan Jia ${ }^{\text {h }}$ Charmian A. Quigley ${ }^{i}$ Werner F. Blum ${ }^{j}$ \\ ${ }^{a}$ Endocrinology and Diabetes Unit, Eli Lilly, Neuilly-sur-Seine, France; b Lilly Research Laboratories, \\ Windlesham, UK; ' Department of Pediatric Endocrinology and Diabetology, and INSERM U690, University Paris 7, \\ Denis Diderot, Hôpital Robert Debré, Paris, France; ${ }^{d}$ Department of Pediatrics, Thomas Jefferson University, \\ Philadelphia, PA, and ${ }^{~}$ DuPont Hospital for Children, Wilmington, DE, USA; ${ }^{f}$ University of Montreal and CHU Ste-Justine, \\ Montreal, QC, Canada; ${ }^{9}$ Department of Pediatrics, Erasmus Medical Centre Sophia, Rotterdam,

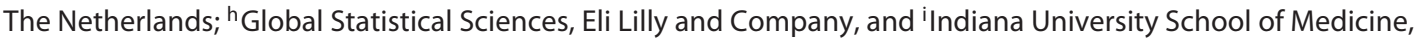 \\ Indianapolis, IN, USA; 'University Children's Hospital, University of Giessen, Giessen, Germany
}

\section{Key Words}

SHOX deficiency $\cdot$ Growth hormone treatment $\cdot$ Short stature · Growth · Safety · Near-adult height

\section{Abstract \\ Background/Aims: To assess auxological and safety data for growth hormone (GH)-treated children with SHOX deficien- cy. Methods: Data were examined for GH-treated SHOX-de- ficient children $(n=521)$ from the observational Genetics and Neuroendocrinology of Short Stature International Study (GeNeSIS). For patients with near-adult height infor- mation, GeNeSIS results ( $n=90)$ were compared with a clin- ical trial $(n=28)$ of SHOX-deficient patients. Near-adult height was expressed as standard deviation score (SDS) for chronological age, potentially increasing the observed ef- fect of treatment. Results: Most SHOX-deficient patients in GeNeSIS had diagnoses of Leri-Weill syndrome $(n=292)$ or non-syndromic short stature $(n=228)$. For GeNeSIS patients with near-adult height data, mean age at $\mathrm{GH}$ treatment start}

\begin{tabular}{ll}
\hline KARGER & $\begin{array}{l}\text { (c) 2016 The Author(s) } \\
\text { Published by S. Karger AG, Basel }\end{array}$ \\
E-Mail karger@karger.com & $\begin{array}{l}\text { Karger } \\
\text { www.karger.com/hrp }\end{array}$ \\
& $\begin{array}{l}\text { This article is licensed under the Creative Commons Attribution- } \\
\text { NonCommercial-NoDerivatives 4.0 International License (CC BY- } \\
\text { NC-ND) (http://www.karger.com/Services/OpenAccessLicense) } \\
\text { Usage and distribution for commercial purposes as well as any dis- } \\
\text { tribution of modified material requires written permission. }\end{array}$
\end{tabular}

was 11.0 years, treatment duration 4.4 years, and height SDS gain 0.83 (95\% confidence interval 0.49-1.17). Respective ages, GH treatment durations and height SDS gains for GeNeSIS patients prepubertal at baseline $(n=42)$ were 9.2 years, 6.0 years and $1.19(0.76-1.62)$, and for the clinical trial cohort they were 9.2 years, 6.0 years and $1.25(0.92-1.58)$. No new GH-related safety concerns were identified. Conclusion: Patients with SHOX deficiency who had started GH treatment before puberty in routine clinical practice had a similar height gain to that of patients in the clinical trial on which approval for the indication was based, with no new safety concerns.

(C) 2016 The Author(s)

Published by S. Karger AG, Basel

\section{Introduction}

Growth is influenced by many factors, both genetic and environmental, and short stature is a frequent reason for referral to a paediatric endocrinologist. One of the 
many genes involved in statural growth is the short stature homeobox-containing (SHOX) gene located in the pseudoautosomal region (PAR1) of the $\mathrm{X}$ and $\mathrm{Y}$ chromosomes $[1,2]$. This gene may be affected by mutations and deletions in the coding region and in the enhancer regions [1-5]. Deficiency of the gene product results in a broad spectrum of phenotypic characteristics, including variable degrees of impaired growth [2, 6-8]. In addition to short stature, children with SHOX deficiency may also have skeletal anomalies consistent with mesomelic skeletal dysplasia, including short forearms and lower legs, and bowing of the forearms [2,7-10]. Such clinical signs are typical of Leri-Weill syndrome (LWS); however, some children with SHOX deficiency may have no evidence of skeletal dysplasia, identifiable clinical anomalies, or other definable causes for their short stature [8-10].

Girls and women with Turner syndrome lack all or part of the second sex chromosome and, therefore, have only one copy of SHOX; this haploinsufficiency underlies a substantial portion of the short stature seen in patients with Turner syndrome [11]. Many studies have demonstrated increased adult height following growth hormone $(\mathrm{GH})$ therapy in patients with Turner syndrome [12-16]. For this reason, GH therapy was examined in patients with non-Turner syndrome SHOX deficiency, and several studies have now shown that GH can have a positive effect on the growth of SHOX-deficient patients [16-19].

Approval for the indication of $\mathrm{GH}$ treatment of short stature due to SHOX deficiency was based on data from the 2-year randomised treatment phase of a single clinical trial [17]. After completion of this randomised phase, all participants were offered GH therapy until attainment of near-adult (final) height [16]. It is important to determine whether results from clinical trials are matched by subsequent outcomes in routine clinical practice. Observational programmes, such as the Genetics and Neuroendocrinology of Short Stature International Study (GeNeSIS), are carried out to assess safety and effectiveness outcomes of children with growth disorders, with or without GH treatment. The present study aimed to analyse GeNeSIS data for patients with short stature associated with SHOX deficiency and to evaluate long-term effects of GH therapy on safety and near-adult height. Results for patients who achieved near-adult height during this observational study were assessed in relation to results from the previously published clinical trial of GH-treated SHOX-deficient patients $[16,17]$.

Outcomes of GH-Treated Children with

SHOX Deficiency

\section{Methods}

Patient Populations

GeNeSIS (ClinicalTrials.gov: NCT 01088412) was a prospective multinational, open-label, paediatric surveillance programme designed to examine the long-term safety and efficacy of $\mathrm{GH}(\mathrm{Hu}-$ matrope ${ }^{\circledR}$, Eli Lilly and Company, Indianapolis, IN, USA) administered for treatment of short stature. Patients were enrolled from March 1999 to September 2013. Among the causes of short stature, the database includes paediatric patients who have received $\mathrm{GH}$ therapy for short stature associated with SHOX deficiency. SHOX deficiency was diagnosed by investigators on the basis of clinical signs of LWS and/or molecular genetic data available at the time of presentation or study enrolment. Patients enrolled in GeNeSIS and diagnosed by investigators as having Turner syndrome were not included in the present analysis.

Because GeNeSIS was an observational study, all diagnostic and treatment decisions, including study enrolment and GH dose, were made at the discretion of the participating investigator, in accordance with standard paediatric endocrinology practice. The only specific eligibility criterion in GeNeSIS was that patients had open epiphyses.

In the clinical trial (NCT 00190658), carried out from February 2000 to September 2010, patients with SHOX deficiency and short stature were randomised to be either treated with $\mathrm{GH}(0.05 \mathrm{mg} / \mathrm{kg} /$ day) or untreated for the first 2 years [17]. At the end of the randomised period, all patients were offered GH treatment $(0.05 \mathrm{mg}$ / $\mathrm{kg} /$ day) until near-adult height was attained or until study closure. All enrolled patients were at least 3 years of age and were prepubertal (girls: Tanner stage 1 breast development; boys: Tanner stage 1 genital development and testicular volume $\leq 2 \mathrm{~mL}$ ) at the start of GH therapy; other criteria for enrolment and patient characteristics have been described previously $[16,17]$.

Both the GeNeSIS observational study and the clinical trial included patients who were followed until they achieved near-adult (final) height. It was possible for patients in the clinical trial to subsequently be enrolled in GeNeSIS; therefore, it was ascertained that such patients were excluded from analysis within the GeNeSIS cohort and only included in the clinical trial cohort for safety assessments and analysis of patients who achieved near-adult height. Patients who had entered puberty at GH initiation were not excluded from GeNeSIS participation, whereas all patients in the clinical trial were prepubertal when starting GH. Therefore, a subgroup of patients in GeNeSIS who were prepubertal at the time of $\mathrm{GH}$ initiation and who had near-adult height data available was also assessed.

The clinical trial protocol was approved by all appropriate local ethics review committees and the GeNeSIS protocol adhered to the applicable regulatory requirements in the participating countries, with appropriate institutional review board approvals. In both the observational study and the clinical trial, written informed consent for data collection, processing and publication was provided by the parents or a legal guardian for each child, in accordance with national and local regulations. Both studies were performed according to the ethical principles of the Declaration of Helsinki.

\section{Study Evaluations}

Baseline data collected at the entry to GeNeSIS included medical history, physical examination, laboratory values and pubertal status, as provided by the attending physician. Medical history in- 
cluded the investigator-defined diagnosis of the cause of short stature, previous laboratory data and pre-existing medications. Baseline clinical variables included height, weight, parental heights (for the calculation of the genetic target height [sex-adjusted average of parental heights]) and bone age. Pubertal stage was evaluated according to the Tanner classification. Height, weight and pubertal stage were documented at follow-up visits.

Baseline data in the clinical trial included medical history, height, weight, parental heights and bone age. All patients had SHOX deficiency confirmed by centralised genetic analysis of the SHOX gene [8]. Investigators also reported the clinical phenotype, with categorisation as either having LWS or non-syndromic short stature. At the start of GH therapy, all patients were prepubertal (Tanner stage 1), had no evidence of GH deficiency or resistance and were not taking any growth-influencing medications. Height, weight and pubertal development changes were evaluated at follow-up visits.

Patients from GeNeSIS and the clinical trial were considered to have reached near-adult height (final height) during follow-up if they attained one of the following criteria: height velocity $<2 \mathrm{~cm} /$ year, X-ray of the hand showing closed epiphyses or bone age $>14$ years for girls or $>16$ years for boys. Bone age was assessed from radiographs of the left hand and wrist, which were read using Greulich and Pyle standards [20].

The clinical trial predominantly enrolled patients from central European countries; therefore, standard deviation scores (SDS) for height were calculated for both GeNeSIS and the clinical trial using data from a central European reference population [21]. Nearadult height was expressed as height SDS for chronological age at the time of the measurement, including when adult height was considered as attained, which could potentially increase the observed effect of treatment but is a well-accepted method for SDS calculation. Body mass index SDS was determined from European reference data [22].

Safety analysis for inclusion in this report was based on adverse events reported for patients who received GH therapy. Serious adverse events (SAEs) were defined as any event that resulted in death, hospitalisation, persistent or significant disability, or congenital anomaly in the offspring of a treated patient, were considered life-threatening or were significant for another reason in the opinion of the investigator. Treatment-emergent adverse events (TEAEs) were assessed for patients who had at least one follow-up visit after starting GH therapy and were defined as events that first occurred or worsened in severity. All adverse events were categorised according to the Medical Dictionary for Regulatory Authorities (MedDRA, version 11.0).

\section{Genetic Analyses}

Patients enrolled in GeNeSIS could have a diagnosis of SHOX deficiency on the basis of clinical signs, with no requirement to have a proven SHOX gene alteration, and underwent genetic testing only at the discretion of the investigator. Therefore, the molecular technique varied according to the laboratory carrying out the genetic testing. In France, the analyses were carried out by the Necker-Enfants Malades hospital group, Paris, as previously described [23]. Samples from other European countries were mainly analysed at Bioscientia, Germany, although some were analysed at other local laboratories; samples from US sites were analysed at Esoterix Endocrinology, Calabasas Hills, CA, USA. Analysis of the downstream and upstream enhancer regions for the SHOX gene was carried out for a limited number of patients who had entered GeNeSIS more recently.

In the clinical trial, all patients were required to have a demonstrated SHOX gene alteration, based on central laboratory analysis [8]. The enhancer domains for the SHOX gene had not been identified at the time of screening for the clinical trial and were, therefore, not analysed.

\section{Statistics}

Data for patients with SHOX deficiency in GeNeSIS were analysed using descriptive statistics. Results for continuous variables are presented as means \pm SD with $95 \%$ confidence intervals (CIs). Information on categorical variables is presented as number of patients and percentage of the relevant total population. Safety data were assessed for all patients who received GH treatment in both GeNeSIS and the clinical trial. Near-adult heights were assessed using mean and 95\% CI of height SDS for age at the time of measurement.

\section{Results}

\section{Baseline Data for Patients with SHOX Deficiency in GeNeSIS}

At the March 2014 data lock for this report, the GeNeSIS database contained evaluable information for 21,577 GH-treated paediatric patients, including 521 patients (314 female, 207 male) with a diagnosis of SHOX deficiency enrolled between 2000 and 2013. The majority of the GH-treated SHOX-deficient patients were from Germany $(n=197)$ and France $(n=180)$, followed by the USA ( $\mathrm{n}=61)$, Spain $(n=25)$ and Czech Republic $(n=20)$, with the remainder spread among 11 other countries.

Among the 521 patients, the numbers with an investigator-provided diagnosis of either LWS (56\%) or nonsyndromic short stature (44\%) are shown in Figure 1, together with available information on identified gene defects. Molecular alterations affecting the SHOX gene, as described by the investigator, were reported for 207 (71\%) of the 292 patients with a diagnosis of LWS. Of these, 194 patients $(66 \%)$ had a reported molecular alteration encompassing the SHOX gene, with or without a reported alteration in the PAR1, and 12 (4\%) had identified alterations in the regulatory regions of the SHOX gene only; the nature of the genetic alteration was not specified for 1 patient. The majority of the SHOX alterations were complete or partial deletions involving the coding region $(153 / 207=74 \%), 16 \%$ were missense or nonsense mutations and $1 \%$ were partial duplications. No alteration of the SHOX gene or PAR1 was identified for $54(18 \%)$ of the patients with LWS phenotype. Of the 228 patients with non-syndromic SHOX deficiency, alterations in the SHOX gene were identified in 218 , comprising deletions 


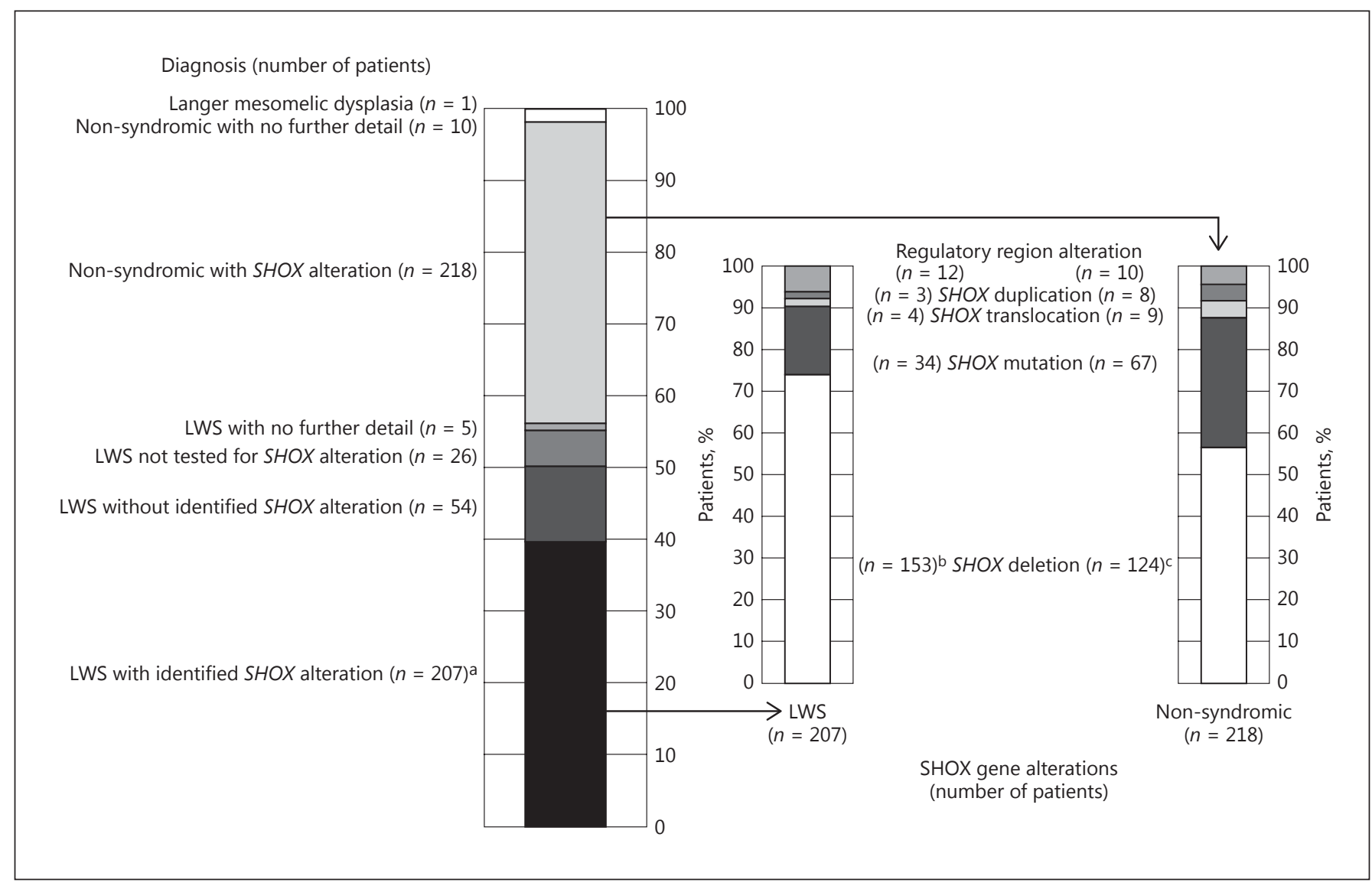

Fig. 1. Summary of specific diagnoses and $S H O X$ gene alterations of patients in GeNeSIS with a diagnosis of SHOX deficiency. Assignments of genetic alterations are based on the available reported data and reflect the classification of individual patients by their clinician. ${ }^{a}$ Included 1 patient with a gene alteration that was not specified. ${ }^{\mathrm{b}}$ Included SHOX deletion ( $n=106$ [51\% of 207 with SHOX alterations]), SHOX + PAR1 deletion ( $n=35[17 \%])$, SHOX

for 124 (57\%), mutations for 67 (31\%), and other variations for $27(12 \%)$.

Baseline characteristics of all patients with SHOX deficiency in GeNeSIS are summarised in Table 1. Mean age at the start of GH treatment was 9.4 \pm 3.2 (95\% CI 9.1-9.6) years. Mean height SDS was $-3.01 \pm 0.77$ (95\% CI -3.08 to -2.94$)$, and mean initial GH dose was $0.30 \pm 0.09$ (95\% CI $0.29-0.31) \mathrm{mg} / \mathrm{kg} /$ week.

\section{Safety Information}

For 514 patients with SHOX deficiency in GeNeSIS, with available information, mean duration of follow-up was $2.8 \pm 2.0$ years. One death was reported and 3 patients discontinued due to adverse events. In the clinical trial, 49 patients received $\mathrm{GH}$ for a mean duration of $7.0 \pm 1.8$ partial deletion $(n=9[4 \%])$ and SHOX + PAR1 partial deletion $(n=3[1 \%]) .{ }^{c}$ Included SHOX deletion $(n=100$ [46\% of 218 with SHOX alterations]), SHOX + PAR1 deletion $(n=19$ [9\%]), PAR1 deletion $(n=1[<1 \%])$ and SHOX partial deletion $(n=4[2 \%])$. LWS, Leri-Weill syndrome; SHOX, short stature homeobox-containing gene. years for those initially randomised to $\mathrm{GH}(n=26)$ and $4.8 \pm 2.0$ years for those randomised to be untreated with $\mathrm{GH}$ for the first 2 years $(n=23)$; there were no reported deaths or discontinuations due to adverse events.

In GeNeSIS, 14 SAEs were reported for 12 patients (appendicitis $[n=2]$, chronic renal failure $[n=2]$, adenoidectomy, death, hypertension, ligament injury, limb operation, lower limb fracture, neoplasm recurrence, osteomyelitis, post-streptococcal glomerulonephritis, and spondylolisthesis). The SAE reported as death was a girl diagnosed with LWS, with no identified SHOX gene defect; she received a kidney transplant following chronic renal failure, had received GH for approximately 2 years and 4 months, and died 18 months after discontinuing $\mathrm{GH}$. The neoplasm recurrence was a relapse of pilocytic 
Table 1. Characteristics at the start and height gain after 1 year of $\mathrm{GH}$ treatment of patients with SHOX deficiency in the GeNeSIS observational programme

\begin{tabular}{ll}
\hline & $\begin{array}{l}\text { Children with SHOX } \\
\text { deficiency }(n=521)^{\mathrm{a}}\end{array}$ \\
\hline Female/male & $314(60.3) / 207(39.7)$ \\
Tanner stage 1 (female/male), \% & $69.0 / 83.6$ \\
Age, years & $9.4 \pm 3.2(9.1$ to 9.6$)$ \\
Bone age delay, years & $-0.9 \pm 1.2(-1.1$ to -0.8$)$ \\
Height SDS & $-3.01 \pm 0.77(-3.08$ to -2.94$)$ \\
Target height SDS & $-1.14 \pm 0.93(-1.23$ to -1.06$)$ \\
Height SDS - target height SDS & $-1.87 \pm 1.05(-1.96$ to -1.77$)$ \\
GH dose, mg/kg/week & $0.30 \pm 0.09(0.29$ to 0.31$)$ \\
First year gain in height SDS & $0.53 \pm 0.51(0.47$ to 0.59$)$ \\
\hline
\end{tabular}

Data show number of patients (\% of total) or mean \pm SD $(95 \%$ CI). CI, confidence interval; SD, standard deviation; SDS, standard deviation score; SHOX, short stature homeobox-containing gene.

a Total number of patients with evaluable data, but patient numbers may be lower for individual parameters. ${ }^{\mathrm{b}}$ Evaluable for 277 patients.

astrocytoma approximately 1 year and 11 months after $\mathrm{GH}$ initiation.

In the clinical trial, 10 SAEs were reported for 6 patients (epilepsy $[n=2]$, abdominal pain, acute seizure, appendicitis, arthritis, Crohn disease, inguinal hernia, tonsillar hypertrophy, and vomiting). The 2 epilepsy events and the acute seizure all occurred in 1 patient.

No TEAEs were reported for 397 (80\%) of the 495 patients with SHOX deficiency in GeNeSIS who had at least one follow-up visit after starting GH therapy. A TEAE was reported for 98 patients (20\%); the most frequent were precocious puberty and arthralgia (Table 2). For the 49 patients in the clinical trial, $43(87.8 \%)$ reported at least 1 TEAE; the majority were for common childhood illnesses, particularly infections and infestations reported for 32 patients $(65 \%)$. Scoliosis was reported for $5(10 \%)$ patients in the clinical trial and $2(0.4 \%)$ patients in GeNeSIS. There were no reports of diabetes mellitus in the GH-treated patients with SHOX deficiency in either study.

\section{Near-Adult Height Data}

Near-adult height data were available at the time of analysis for $90 \mathrm{GH}$-treated patients with SHOX deficiency in GeNeSIS, 42 of whom were prepubertal at baseline; near-adult height data were available for 28 patients in the clinical trial, all of whom were prepubertal at baseline.
Table 2. Reported SAEs and TEAEs during GH treatment of patients with SHOX deficiency in GeNeSIS and the clinical trial

\begin{tabular}{lcl}
\hline & GeNeSIS & Clinical trial \\
\hline Number of GH-treated patients & 521 & 49 \\
Patients with $\geq 1$ SAE & $12(2.3 \%)$ & $6(12.2 \%)$ \\
Number of GH-treated patients & & \\
$\quad$ with follow-up & 495 & 49 \\
Patients with $\geq 1$ TEAE & $98(19.8 \%)$ & $43(87.8 \%)$ \\
TEAEs reported most frequently & & \\
Precocious puberty & $13(2.6 \%)$ & $1(2.0 \%)$ \\
Arthralgia & $12(2.4 \%)$ & $6(12.2 \%)$ \\
Headache & $8(1.6 \%)$ & $9(18.4 \%)$ \\
Hypothyroidism & $6(1.2 \%)$ & $1(2.0 \%)$ \\
Back pain & $5(1.2 \%)$ & $4(8.2 \%)$ \\
Madelung deformity & $2(0.4 \%)$ & $8(16.3 \%)$ \\
Nasopharyngitis & $1(0.2 \%)$ & $7(14.3 \%)$ \\
Ear infection & $1(0.2 \%)$ & $6(12.2 \%)$ \\
Cough & $1(0.2 \%)$ & $6(12.2 \%)$ \\
Congenital bowing of long bones & 0 & $9(18.4 \%)$ \\
Vomiting & 0 & $6(12.2 \%)$ \\
\hline
\end{tabular}

$\mathrm{GH}$, growth hormone; SAE, serious adverse event; SHOX, short stature homeobox-containing gene; TEAE, treatmentemergent adverse event.

${ }^{a}$ MedDRA preferred terms; events reported in $>1 \%$ of patients in GeNeSIS or $>12 \%$ of clinical trial patients. ${ }^{b}$ MedDRA preferred term states congenital, reflecting the initial clinical observation of Madelung deformity during study participation.

The genotype and phenotype data for these patients are shown in Table 3. In both GeNeSIS and the clinical trial, the majority of patients with available near-adult height data had a diagnosis of LWS. For patients in GeNeSIS with genetic data available, the proportions with an identified mutation, deletion or duplication were very similar to the proportions identified during screening for the clinical trial (Table 3).

Patient characteristics, auxological parameters and GH treatment details at GH initiation and near-adult height are summarised in Table 4. The mean age at GH start was greater for the full group of 90 patients with near-adult height data in GeNeSIS than for the patients in the clinical trial; however, the mean age of the 42 prepubertal patients in this subgroup of GeNeSIS was similar to that of the patients in the clinical trial (Table 4). Mean age at near-adult height for both the full group and the prepubertal subgroup of patients in GeNeSIS was similar to that of the patients in the clinical trial. Thus, mean treatment duration was shorter for the complete GeNeSIS cohort with near-adult height data than for patients in the 
clinical trial, whereas GeNeSIS patients who started GH when prepubertal had a treatment duration similar to that of patients in the clinical trial. Initial and last reported doses of GH were lower for the full cohort of GeNeSIS patients with near-adult height data than for patients in the clinical trial. For the GeNeSIS patients who were prepubertal at the GH start, the initial GH dose was similar to that for the patients in the clinical trial, but the last reported dose was lower.

Height SDS at baseline and near-adult height, as well as change in height SDS are shown in Figure 2. Mean change in height SDS from GH start to near-adult height was 0.83 (95\% CI 0.49-1.17) for the full GeNeSIS cohort and 1.19 (95\% CI 0.76-1.62) for the prepubertal subgroup in GeNeSIS, compared with 1.25 (95\% CI 0.92-1.58) for patients in the clinical trial. At the time of near-adult height measurement, $53 \%$ of the patients in GeNeSIS and $57 \%$ of the patients in the clinical trial had height above the lower limit of the normal range (>-2 SDS).

\section{Discussion}

Among patients enrolled in the GeNeSIS observational study and treated with GH in routine clinical practice, a diagnosis of SHOX deficiency was reported by physicians for 521 patients. For $56 \%$ of these patients the diagnosis was reported as LWS, and for $44 \%$ the phenotype was reported to be "non-syndromic" SHOX deficiency (also known as "idiopathic" short stature). This phenotype distribution was similar to the approximately equal proportions of LWS versus idiopathic short stature for the total cohort included in the clinical trial [17]. There was also $1 \mathrm{GH}$-treated patient in GeNeSIS with a diagnosis of Langer mesomelic dysplasia, the homozygous form of SHOX deficiency; although GH treatment may have limited effectiveness in promoting height gain in patients with this condition, the patient was included in the analysis in reflection of the real-world nature of data from an observational study. All of the patients with SHOX deficiency had severe growth impairment at baseline, and GH treatment for 1 year was associated with a mean height SDS gain of 0.53 .

The genetic information in GeNeSIS was as provided by the investigators, with different analysis techniques used over a long enrolment period. However, the data showed that the majority of the genetic alterations for patients in GeNeSIS were complete or partial deletions of the SHOX gene. Consistent with previous reports, enrolled patients more commonly had deletions of the

Table 3. Phenotype and genotype information for patients with SHOX deficiency for whom near-adult height data were reported at the time of analysis

$\begin{array}{ll}\begin{array}{l}\text { GeNeSIS } \\ (n=90)\end{array} & \begin{array}{l}\text { Clinical trial } \\ (n=28)\end{array}\end{array}$

\section{Phenotype}

Leri-Weill syndrome $\quad 56(62 \%) \quad 17(61 \%)$

Non-syndromic short stature $\quad 34(38 \%) \quad 11(39 \%)$

Genotype

Deletion

Mutation

Translocation

Duplication

Regulatory region alteration

No identified alteration/no test

$\begin{array}{cl}43(48 \%)[77 \%] & 22(79 \%) \\ 9(10 \%)[16 \%] & 5(18 \%) \\ 1(1 \%)[2 \%] & 0 \\ 1(1 \%)[2 \%] & 1(4 \%) \\ 2(2 \%)[4 \%] & \text { N/A } \\ 34(38 \%) & \text { N/A }\end{array}$

Data show numbers of patients with phenotype/genotype (percentage of total number of patients for whom near-adult height was reported) [percentage of the $56 \mathrm{GeNeSIS}$ patients with identified genetic alteration for whom near-adult height was reported]. Assignments of genetic alterations were based on the available reported data and reflect the classification of individual patients by their clinician. N/A, not applicable; SHOX, short stature homeobox-containing gene.

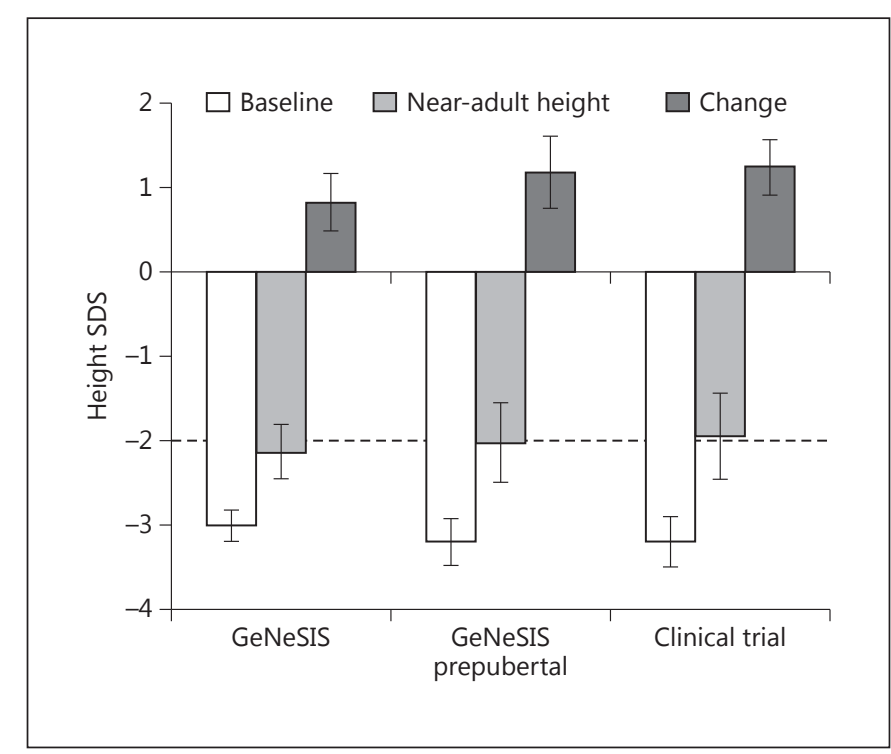

Fig. 2. Height standard deviation score at the start of growth hormone treatment and at near-adult height, with change from baseline to near-adult height, for patients who attained near-adult height during GeNeSIS follow-up, patients who were prepubertal (Tanner 1) and reached near-adult height during GeNeSIS, and those who reached near-adult height in the clinical trial [16]. Bars show means with 95\% confidence intervals; dashed line indicates lower limit of normal height range. SDS, standard deviation score. 
Table 4. Demographics, auxology and GH treatment profile at baseline (GH initiation) and at near-adult height for all patients in GeNeSIS, the subgroup of patients in GeNeSIS who were prepubertal (Tanner stage 1) at GH start, and patients in the clinical trial, for whom NAH was attained during follow-up

\begin{tabular}{llll}
\hline & GeNeSIS & & $\begin{array}{l}\text { Clinical trial } \\
\text { (n=28) }\end{array}$ \\
\cline { 2 - 3 } & all $(n=90)$ & prepubertal $(n=42)$ & $15(53.6)$ \\
\hline Female, $n(\%)$ & $59(65.6)$ & $32(76.2)$ & $9.2 \pm 2.4(8.3$ to 10.2$)$ \\
Age at GH initiation, years & $11.0 \pm 2.4(10.5$ to 11.5$)$ & $9.2 \pm 2.2(8.6$ to 9.9$)$ & $15.5 \pm 1.3(15.0$ to 16.0$)$ \\
Age at NAH, years & $15.7 \pm 1.4(15.4$ to 16.0$)$ & $15.5 \pm 1.3(15.1$ to 15.9$)$ & $-0.9 \pm 0.7(-1.2$ to -0.7$)$ \\
Bone age delay at baseline, years & $-0.6 \pm 1.5(-1.0$ to -0.2$)$ & $-0.9 \pm 1.6(-1.5$ to -0.3$)$ & $-3.20 \pm 0.77(-3.50$ to -2.90$)$ \\
Height SDS at baseline & $-3.01 \pm 0.87(-3.19$ to -2.83$)$ & $-3.20 \pm 0.88(-3.48$ to -2.93$)$ & $-1.6 \pm 0.9(-1.92$ to -1.19$)$ \\
Target height SDS & $-1.14 \pm 0.89(-1.33$ to -0.95$)$ & $-1.21 \pm 0.77(-1.46$ to -0.97$)$ & NA \\
NAH SDS - target height SDS & $-0.96 \pm 1.41(-1.28$ to -0.64$)$ & $-0.78 \pm 1.21(-1.18$ to -0.38$)$ & $0.36 \pm 0.02(0.35$ to 0.37$)$ \\
GH dose at start, mg/kg/week & $0.32 \pm 0.10(0.30$ to 0.34$)$ & $0.34 \pm 0.08(0.31$ to 0.37$)$ & $0.38 \pm 0.02(0.37$ to 0.38$)$ \\
GH dose last reported, $\mathrm{mg} / \mathrm{kg} /$ week & $0.33 \pm 0.10(0.30$ to 0.35$)$ & $0.33 \pm 0.10(0.30$ to 0.36$)$ & $6.02 \pm 2.01(5.24$ to 6.79$)$ \\
Treatment duration, years & $4.40 \pm 2.33(3.91$ to 4.90$)$ & $5.98 \pm 2.15(5.31$ to 6.65$)$ & \\
\hline
\end{tabular}

Data show mean \pm SD (95\% CI). CI, confidence interval; GH, growth hormone; NA, not available; NAH, near-adult height; SD, standard deviation; SDS, standard deviation score; SHOX, short stature homeobox-containing gene.

SHOX gene than single base mutations [2, 24, 25]. Prevalence of deletions versus point mutations was greater in the patients with LWS phenotype than in those with the non-syndromic phenotype, suggesting that the phenotype may correlate to some extent with the magnitude of the genetic alteration. Alterations in the SHOX regulatory region were only found in 5-6\% of the patients with LWS and non-syndromic SHOX deficiency (18\% of patients with LWS and 9\% of those with non-syndromic SHOX deficiency had deletions that also extended to other parts of PAR1, potentially including regulatory elements). The relatively small number of patients in GeNeSIS with identifiable alterations in the regulatory regions of the SHOX gene $[26,27]$ is most likely due to the fact that, during the enrolment period from 1999 to 2013, screening for alterations in enhancer elements was not uniformly performed in genetic laboratories $[6,8,25,28]$.

Analysis of the GeNeSIS patients known to be prepubertal at GH initiation showed that they had a similar mean height SDS gain from the start of GH treatment to that seen for the patients in the clinical trial. In both cohorts, substantial mean height SDS gains of approximately 1.2 (equivalent to approximately $8 \mathrm{~cm}$ ) were observed. Apart from the previous report of the clinical trial, the only other study to date that has reported final height/ near-adult height data for GH-treated patients with SHOX deficiency found a mean height SDS gain of 0.6 in a group of 5 peripubertal patients who were treated with a gonadotropin-releasing hormone analogue for pubertal suppression and started GH at a mean age of 11.6 years
[29]. These findings suggest that, similar to other short stature indications for $\mathrm{GH}$ treatment, height gain is greater when GH is initiated early, particularly before onset of puberty $[30,31]$. However, the use of height SDS for chronological age of the near-adult height measurement in children with a mean age of 15.7 years may not accurately measure the true adult height SDS.

Identification of patients with potential SHOX deficiency when prepubertal can be challenging, especially in boys, because most young children with SHOX deficiency lack specific clinical signs such as high-arched palate or Madelung deformity [32,33]. Careful measurement of body proportions can elicit more subtle markers of SHOX deficiency, such as increased sitting height-to-height ratio and reduced extremities-to-trunk ratio [32, 34]. Furthermore, meticulous examination of the parents for Madelung deformity, complemented by forearm X-rays of the child, can facilitate an earlier diagnosis of SHOX deficiency in a prepubertal child with non-syndromic short stature [2].

The phenotypes and genotypes were very similar for the prepubertal patients with SHOX deficiency in GeNeSIS and the patients in the clinical trial. Thus, the similar height gains observed for the prepubertal GeNeSIS and clinical trial cohorts would indicate that the clinical trial data on which the relevant approval was based are reasonably generalisable to that of patients with SHOX deficiency in routine clinical practice, when $\mathrm{GH}$ is initiated before the start of puberty.
48
Horm Res Paediatr 2017;87:42-50 DOI: $10.1159 / 000452973$
Benabbad/Rosilio/Child/Carel/Ross/Deal/ Drop/Zimmermann/Jia/Quigley/Blum 
Analysis of safety information from the GH-treated patients with SHOX deficiency in GeNeSIS did not indicate any new concerns. The proportion of patients for whom at least 1 TEAE was reported was substantially greater in the clinical trial than in GeNeSIS; this was not unexpected because adverse event reporting was mandated in the clinical trial, whereas patients and investigators are less likely to report adverse events during routine clinical management and treatment. There was no evidence for excessive bone maturation or any worsening of dysmorphic or skeletal features. Scoliosis was reported at a low incidence: 5 cases in the clinical trial, of which 1 was considered by the investigators to be possibly related to $\mathrm{GH}$ treatment, and 2 cases reported in the GeNeSIS population, both of which were considered to be unrelated to $\mathrm{GH}$ treatment. Although precocious puberty was reported for 13 patients $(2.6 \%)$ in GeNeSIS, further investigation showed that most of these cases did not meet the accepted criteria for diagnosis (i.e. breast development before 8 years of age in girls and testicular enlargement before 9 years of age in boys).

In conclusion, among patients who were treated with GH for short stature associated with SHOX deficiency in GeNeSIS, 56\% had an investigator-provided diagnosis of LWS and $44 \%$ had a diagnosis of non-syndromic SHOX deficiency. These proportions for clinical phenotype of patients in routine clinical practice were similar to those for patients identified in the defining clinical trial [16]. The majority of identified alterations involving the SHOX gene were deletions, and a minority of patients had missense and nonsense mutations, duplications and translocations. Near-adult height gain for patients in GeNeSIS who were prepubertal at GH start was similar to that for patients in the clinical trial, indicating that the clinical trial results were broadly reflective of the response of patients with SHOX deficiency to GH treatment under stan- dard clinical conditions. It remains important to identify patients with short stature due to SHOX deficiency as early as possible, because GH treatment is most effective when started at a young age.

\section{Acknowledgements}

Both GeNeSIS and the clinical trial were sponsored by Eli Lilly and Company. The authors are grateful to Valérie Cormier (Inserm U781, Paris, France) for assistance with interpretation of genetic alterations. Medical writing assistance was provided by Peter Bates (CMWS, UK) and Caroline Spencer (Rx Communications, UK) funded by Eli Lilly and Company. The authors thank all of the investigators who participated in the two studies and all of the patients and their families.

\section{Disclosure Statement}

Imane Benabbad, Myriam Rosilio, Christopher J. Child, Alan G. Zimmermann, and Nan Jia are employees and minor stockholders of Eli Lilly and Company.

Jean-Claude Carel is an investigator in clinical trials using GH sponsored by Pfizer and Eli Lilly and Company, an investigator in postmarketing studies with several brands of $\mathrm{GH}$, and has received support for travel to international meetings from Ipsen and Sandoz.

Judith L. Ross has received research support from Versartis and Novo Nordisk and is a consultant for Novo Nordisk and Pfizer.

Cheri L. Deal has received grants/research support from Eli Lilly and Company, EMD Serono, Sandoz, Versartis and OPKO Health, honoraria or consultation fees from Eli Lilly and Company, EMD Serono, Sandoz, Pfizer and Roche, educational grants to support fellowship training and CME activities from Eli Lilly and Company, EMD Serono, Sandoz and Pfizer and has participated in a company-sponsored speaker's bureau for Eli Lilly and Company, Sandoz, EMD Serono, Roche, and Novo Nordisk.

Stenvert L.S. Drop has no conflicts of interest to declare. Charmian A. Quigley and Werner F. Blum are former employees of Eli Lilly and Company. Werner F. Blum is currently a stockholder and consultant of Eli Lilly and Company.

\section{References}

1 Rao E, Weiss B, Fukami M, Rump A, Niesler B, Mertz A, Muroya K, Binder G, Kirsch S, Winkelmann M, Nordsiek G, Heinrich U, Breuning MH, Ranke MB, Rosenthal A, Ogata T, Rappold GA: Pseudoautosomal deletions encompassing a novel homeobox gene cause growth failure in idiopathic short stature and Turner syndrome. Nat Genet 1997; 16:54-63.

2 Binder G: Short stature due to SHOX deficiency: genotype, phenotype, and therapy. Horm Res Paediatr 2011;75:81-89.
3 Benito-Sanz S, Aza-Carmona M, RodríguezEstevez A, Rica-Etxebarria I, Gracia R, Campos-Barros A, Heath KE: Identification of the first PAR1 deletion encompassing upstream SHOX enhancers in a family with idiopathic short stature. Eur J Hum Genet 2012;20:125127.

4 Durand C, Bangs F, Signolet J, Decker E, Tickle C, Rappold G: Enhancer elements upstream of the SHOX gene are active in the developing limb. Eur J Hum Genet 2010;18:527-532.
5 Chen J, Wildhardt G, Zhong Z, Röth R, Weiss B, Steinberger D, Decker J, Blum WF, Rappold G: Enhancer deletions of the SHOX gene as a frequent cause of short stature: the essential role of a $250 \mathrm{~kb}$ downstream regulatory domain. J Med Genet 2009;46:834-839.

6 Munns CF, Glass IA, Flanagan S, Hayes M, Williams B, Berry M, Vickers D, O'Rourke P, Rao E, Rappold GA, Hyland VJ, Batch JA: Familial growth and skeletal features associated with SHOX haploinsufficiency. J Pediatr Endocrinol Metab 2003;16:987-996. 
7 Ross JL, Kowal K, Quigley CA, Blum WF, Cutler GB Jr, Crowe B, Hovanes K, Elder FF, Zinn AR: The phenotype of short stature homeobox gene (SHOX) deficiency in childhood: contrasting children with Leri-Weill dyschondrosteosis and Turner syndrome. J Pediatr 2005;147:499-507.

8 Rappold G, Blum WF, Shavrikova EP, Crowe BJ, Roeth R, Quigley CA, Ross JL, Niesler B: Genotypes and phenotypes in children with short stature: clinical indicators of SHOX haploinsufficiency. J Med Genet 2007;44: 306-313.

9 Jorge AA, Souza SC, Nishi MY, Billerbeck AE, Libório DC, Kim CA, Arnhold IJ, Mendonca BB: SHOX mutations in idiopathic short stature and Leri-Weill dyschondrosteosis: frequency and phenotypic variability. Clin Endocrinol 2007;66:130-135.

10 de Sanctis V, Tosetto I, Iughetti L, Antoniazzi F, Clementi M, Toffolutti T, Facchin P, Monti E, Pisanello L, Tonini G, Greggio NA: The SHOX gene and the short stature. Roundtable on diagnosis and treatment of short stature due to SHOX haploinsufficiency: how genetics, radiology and anthropometry can help the pediatrician in the diagnostic process Padova (April 20th, 2011). Pediatr Endocrinol Rev 2012;9:727-733.

11 Bondy CA, Matura LA, Wooten N, Troendle J, Zinn AR, Bakalov VK: The physical phenotype of girls and women with Turner syndrome is not X-imprinted. Hum Genet 2007; 121:469-474.

12 Stephure DK; Canadian Growth Hormone Advisory Committee: Impact of growth hormone supplementation on adult height in turner syndrome: results of the Canadian randomized controlled trial. J Clin Endocrinol Metab 2005;90:3360-3366.

13 van Pareren YK, de Muinck Keizer-Schrama SM, Stijnen T, Sas TC, Jansen M, Otten BJ, Hoorweg-Nijman JJ, Vulsma T, StokvisBrantsma WH, Rouwé CW, Reeser HM, Gerver WJ, Gosen JJ, Rongen-Westerlaken C, Drop SL: Final height in girls with Turner syndrome after long-term growth hormone treatment in three dosages and low dose estrogens. J Clin Endocrinol Metab 2003;88: 1119-1125.

14 Rosenfeld RG, Attie KM, Frane J, Brasel JA, Burstein S, Cara JF, Chernausek S, Gotlin RW, Kuntze J, Lippe BM, Mahoney CP, Moore WV, Saenger P, Johanson AJ: Growth hormone therapy of Turner's syndrome: beneficial effect on adult height. J Pediatr 1998; 132:319-324.

15 Bettendorf M, Inta IM, Doerr HG, Hauffa BP, Mehls O, Ranke MB: Height gain in UllrichTurner syndrome after early and late growth hormone treatment start: results from a large retrospective German study and potential basis for an individualized treatment approach. Horm Res Paediatr 2013;80:356-362.
16 Blum WF, Ross JL, Zimmermann AG, Quigley CA, Child CJ, Kalifa G, Deal C, Drop SL, Rappold G, Cutler GB: GH treatment to final height produces similar height gains in patients with SHOX deficiency and Turner syndrome: results of a multicentre trial. J Clin Endocrinol Metab 2013;98:E1383-E1392.

17 Blum WF, Crowe BJ, Quigley CA, Jung $\mathrm{H}$, Cao D, Ross JL, Braun L, Rappold G; SHOX Study Group: Growth hormone is effective in treatment of short stature associated with short stature homeobox-containing gene deficiency: two-year results of a randomized, controlled, multicenter trial. J Clin Endocrinol Metab 2007;92:219-228.

18 Munns CF, Berry M, Vickers D, Rappold GA, Hyland VJ, Glass IA, Batch JA: Effect of 24 months of recombinant growth hormone on height and body proportions in SHOX haploinsufficiency. J Pediatr Endocrinol Metab 2003;16:997-1004

19 Iughetti L, Vannelli S, Street ME, Pirazzoli P, Bertelloni S, Radetti G, Capone L, Stasiowska B, Mazzanti L, Gastaldi R, Maggio MC, Predieri B: Impaired GH secretion in patients with SHOX deficiency and efficacy of recombinant human GH therapy. Horm Res Paediatr 2012; 78:279-287.

20 Greulich W, Pyle S: Radiographic Atlas of Skeletal Development of the Hand and Wrist. Palo Alto, Stanford University, 1959.

21 Flügel B, Greil H, Sommer K: Anthropologischer Atlas. Grundlagen und Daten: Altersund Geschlechtsvariabilität des Menschen. Frankfurt, Wötzel, 1986.

22 Cole TJ: A chart to link child centiles of body mass index, weight and height. Eur J Clin Nut 2002;56:1194-1199.

23 Rosilio M, Huber-Lequesne C, Sapin H, Carel JC, Blum WF, Cormier-Daire V: Genotypes and phenotypes of children with SHOX deficiency in France. J Clin Endocrinol Metab 2012;97:E1257-E1265.

24 Schiller S, Spranger S, Schechinger B, Fukami M, Merker S, Drop SL, Tröger J, Knoblauch H, Kunze J, Seidel J, Rappold GA: Phenotypic variation and genetic heterogeneity in LériWeill syndrome. Eur J Hum Genet 2000;8: 54-62.

25 Rappold GA, Fukami M, Niesler B, Schiller S, Zumkeller W, Bettendorf M, Heinrich U, Vlachopapadoupoulou E, Reinehr T, Onigata K, Ogata T: Deletions of the homeobox gene SHOX (short stature homeobox) are an important cause of growth failure in children with short stature. J Clin Endocrinol Metab 2002;87:1402-1406.
26 Benito-Sanz S, Thomas NS, Huber C, Gorbenko del Blanco D, Aza-Carmona M, Crolla JA, Maloney V, Rappold G, Argente J, Campos-Barros A, Cormier-Daire V, Heath KE: A novel class of Pseudoautosomal region 1 deletions downstream of SHOX is associated with Leri-Weill dyschondrosteosis. Am J Hum Genet 2005;77:533-544.

27 Sabherwal N, Bangs F, Röth R, Weiss B, Jantz K, Tiecke E, Hinkel GK, Spaich C, Hauffa BP, van der Kamp H, Kapeller J, Tickle C, Rappold G: Long-range conserved non-coding SHOX sequences regulate expression in developing chicken limb and are associated with short stature phenotypes in human patients. Hum Mol Genet 2007;16:210-222.

28 Binder G, Renz A, Martinez A, Keselman A, Hesse V, Riedl SW, Häusler G, Fricke-Otto S, Frisch H, Heinrich JJ, Ranke MB: SHOX haploinsufficiency and Leri-Weill dyschondrosteosis: prevalence and growth failure in relation to mutation, sex, and degree of wrist deformity. J Clin Endocrinol Metab 2004;89: 4403-4408.

29 Scalco RC, Melo SS, Pugliese-Pires PN, Funari MF, Nishi MY, Arnhold IJ, Mendonca $\mathrm{BB}$, Jorge AA: Effectiveness of the combined recombinant human growth hormone and gonadotropin-releasing hormone analog therapy in pubertal patients with short stature due to SHOX deficiency. J Clin Endocrinol Metab 2010;95:328-332.

30 Park HK, Lee HS, Ko JH, Hwang IT, Hwang JS: Response to three years of growth hormone therapy in girls with Turner syndrome. Ann Pediatr Endocrinol Metab 2013;18:1318.

31 Pinto G, Cormier-Daire V, Le Merrer M, Samara-Boustani D, Baujat G, Fresneau L, Viaud M, Souberbielle JC, Pineau JC, Polak M: Efficacy and safety of growth hormone treatment in children with hypochondroplasia: comparison with an historical cohort. Horm Res Paediatr 2014;82:355-363.

32 Wolters B, Lass N, Wunsch R, Böckmann B, Austrup F, Reinehr T: Short stature before puberty: which children should be screened for SHOX deficiency? Horm Res Paediatr 2013; 80:273-280.

33 Child CJ, Kalifa G, Jones C, Ross JL, Rappold GA, Quigley CA, Zimmermann AG, Garding G, Cutler GB Jr, Blum WF: Radiological features in patients with short stature homeobox-containing (SHOX) gene deficiency and Turner syndrome before and after 2 years of GH treatment. Horm Res Paediatr 2015:84: 14-25.

34 Binder G, Ranke MB, Martin DD: Auxology is a valuable instrument for the clinical diagnosis of SHOX haploinsufficiency in schoolage children with unexplained short stature. J Clin Endocrinol Metab 2003;88:4891-4896. 